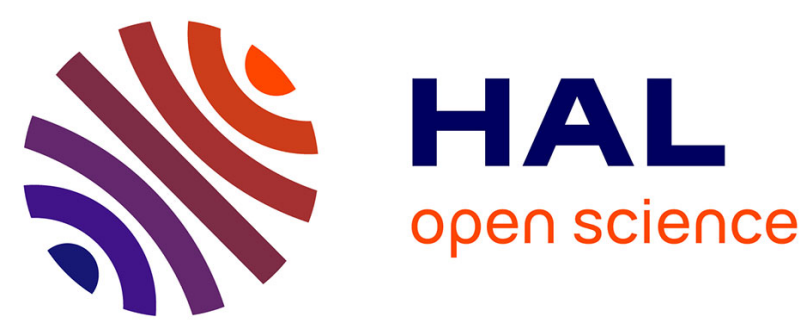

\title{
Analysis of chlorination by-products in swimming pool water by membrane introduction mass spectrometry - influence of water physicochemical parameters
}

Lucie Tsamba, Olivier Correc, Pierre Le Cloirec, Nicolas Cimetiere

\section{- To cite this version:}

Lucie Tsamba, Olivier Correc, Pierre Le Cloirec, Nicolas Cimetiere. Analysis of chlorination byproducts in swimming pool water by membrane introduction mass spectrometry - influence of water physicochemical parameters. Rapid Communications in Mass Spectrometry, 2019, 33 (7), pp.710-718. 10.1002/rcm.8399 . hal-02050273

HAL Id: hal-02050273

https://hal-univ-rennes1.archives-ouvertes.fr/hal-02050273

Submitted on 13 Mar 2019

HAL is a multi-disciplinary open access archive for the deposit and dissemination of scientific research documents, whether they are published or not. The documents may come from teaching and research institutions in France or abroad, or from public or private research centers.
L'archive ouverte pluridisciplinaire HAL, est destinée au dépôt et à la diffusion de documents scientifiques de niveau recherche, publiés ou non, émanant des établissements d'enseignement et de recherche français ou étrangers, des laboratoires publics ou privés. 


\title{
Analysis of chlorination by-products in swimming pool water by Membrane Introduction Mass Spectrometry - Influence of water physicochemical parameters.
}

\author{
Short Title \\ Influence of water physicochemical parameters on MIMS analysis
}

Lucie Tsamba* ${ }^{1,2}$, Olivier Correc $^{2}$, Pierre Le Cloirec $^{1}$ and Nicolas Cimetière ${ }^{1}$

${ }^{1}$ Ecole Nationale Supérieure de Chimie de Rennes, CNRS, UMR 6226, 11 allée de Beaulieu, CS 50837, 35708 Rennes Cedex 7, France

${ }^{2}$ Centre Scientifique et Technique du Bâtiment, AQUASIM, 11 rue Henri Picherit, BP82341, 44323 Nantes Cedex 3, France

*Corresponding author : Email : lucie.tsamba@cstb.fr phone: +33 240376 030)

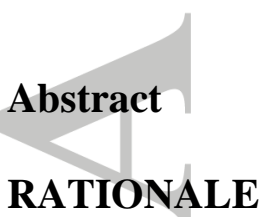

Chlorine reacts in swimming pools with several compounds released by bathers to form disinfection by-products (DBPs). Epidemiological studies have shown adverse effects on health associated with the exposure to DBPs present in indoor swimming pool atmosphere. DBPs analyses require the use of multiple techniques depending on the targeted molecules. The measurement process itself is challenging due to the low stability of several compounds and the lack of specificity of certain methods. The Membrane Introduction Mass Spectrometry (MIMS) technique provides a solution to these problems by specific and sensitive in-situ measurement of DBPs. This study investigates the effect of analytical conditions on DBPs quantification and assesses the relevance of using MIMS for reliable analysis under typical swimming pool operating conditions.

\section{METHODS}

MIMS is based on the simultaneous permeation of the selected compounds from the air or water samples through a polydimethylsiloxane (PDMS) membrane. DBPs are identified and quantified with a quadrupole analyzer after electron ionization. Limits of quantification (LOQ) of 5 DBPs are determined to assess the sensitivity of the system. Moreover, signal changes are monitored while varying physicochemical parameters such as temperature, $\mathrm{pH}$ and ionic strength.

\section{RESULTS}

The mass spectra obtained for individual molecules show that the simultaneous measurement of trihalomethanes (THMs) and chloramines requires the monitoring of several ions and mathematical corrections of the signal. The $\mathrm{pH}$ and ionic strength of the solution does not significantly influence the determination of THMs. On the contrary, the temperature and hydraulics at the membrane interface must be controlled for accurate determination of DBPs.

\section{CONCLUSION}

Results confirm that MIMS is a promising technology for the simultaneous quantification of volatile DBPs in both water and air of swimming pools. However operating conditions such as membrane temperature should be handled with great care in order to avoid interferences.

Keywords: Disinfection by-products, MIMS, Indoor swimming pool, Chloramines, Trihalomethanes.

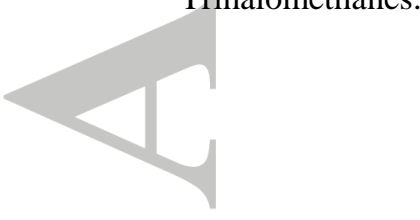




\section{INTRODUCTION}

According to a 2010 study of the French Sports Ministry ${ }^{1}$ swimming is one of the three most recreational sports practiced by French people with walking and cycling. Susceptible individuals like babies or seniors are particularly encouraged to $\mathrm{swim}^{2,3}$. Studies even support the practice of swimming for asthmatic population with a weakened respiratory system ${ }^{4-6}$. It is therefore crucial to ensure that swimming can be practiced with the lowest risk to health. The main risk comes from microbiological infections due to the warm and humid atmosphere of pool halls, which is suitable for bacterial development. Chlorine disinfection is the most commonly used treatment to ensure a good microbiological quality. However, hypochlorous acid reacts with organic material and nitrogen compounds to form disinfection by-products (DBPs) such as halogenated by-products and chloramines. The presence of the DBPs and chloramines precursors is due to the excretion of sweat, urine, saliva, nasal secretions or swimmer cosmetics in pool water ${ }^{7}$. Urea and ammonia are the main components in urine and sweat and they could be responsible for the majority of the DBPs formed in swimming pools. Moreover, some amino acids as well as creatinine and citric acid lead to the formation of DBPs. Numerous studies have shown that the presence of these DBPs in the pool atmospheres has a negative impact on health ${ }^{8-11}$. Trichloramine would cause eyes irritation, predisposition to respiratory allergies and development of asthma ${ }^{12}$. Health disorders related to the exposure to chlorine derivatives are also recognized as occupational diseases for French pool workers since $2003^{13}$. The chlorinated and brominated trihalomethanes are all classified as carcinogenic or potentially carcinogenic substances. Therefore, a better reporting of DBPs concentrations in swimming pool environments is of public health concern. Inhalation is an important way of exposure to volatile DBPs such as trichloramine and chloroform ${ }^{14}$. The volatile fraction of these DBPs is indeed transferred to the ambient air of the pool hall, while the other fraction remains in the bathing water. A better understanding of water/gas transfer mechanisms is crucial to control the DBPs emissions. It requires the development of an analytical method allowing the simultaneous quantification of chlorinated compounds in both phases, which is not possible with the existing techniques. This method would also enable the evaluation of the impact of the remediation treatments (stripping, filters backwash, UV dechlorination/dechloramination, etc.) on the quality of pool and spa environments ${ }^{15,16}$.

Most titrimetric and colorimetric methods are not specific since organic chloramines interfere with the measurements of inorganic chloramines ${ }^{17}$. Other methods including chromatographic techniques appear reliable and reproducible but have numerous disadvantages especially the impossibility of on-line measurement and the necessity of sample pretreatment ${ }^{17}$. The principle of Membrane Introduction Mass Spectrometry (MIMS) is based on the extraction of compounds from the aqueous or gaseous sample using a thin membrane, typically made of polydimethylsiloxane (PDMS), according to the principle of pervaporation. The target compounds are then detected using mass spectrometry. This tool was recently used to evaluate the effectiveness of water treatment processes in a pool ${ }^{16}$. MIMS has the potential to make realtime measurements of many DBPs such as trihalomethanes (THMs) and chloramines ${ }^{17-19}$.

The main advantages of the MIMS technology are the absence of sample processing, the possibility to carry out real-time in-situ measurements over long periods and the ability to measure targeted compounds in both water and air ${ }^{20,21}$. Nevertheless, this innovative method is still not widely used and operating conditions must be optimized. The objective of this bench scale study is to assess the potential of the MIMS method and to determine the optimal conditions for DBPs measurements in indoor pool water and air. Particular attention is paid to 
the influence of the water physicochemical characteristics ( $\mathrm{pH}$, ionic strength and temperature) and to the stirring conditions.

\section{MATERIAL AND METHOD}

All experiments have been performed at lab scale. Procedures adopted for the preparation of solutions and gaseous streams are described in the following sections. All experiments have been performed at $20^{\circ} \mathrm{C}$, unless otherwise noted.

\section{Preparation of solutions}

The $\mathrm{pH}$ and temperature of solutions were measured with a Multi 3430 multimeter (WTW) equipped with a $\mathrm{pH}$-electrode $\mathrm{SenTix}^{\circledR}$ (WTW). Solutions of free chlorine (hypochlorous acid / hypochlorite ion) were obtained by diluting commercial sodium hypochlorite (Organic Accros, Sodium Hypochlorite 13\%) in ultrapure water (UPW, 18.2 M. $\mathrm{cm}$, Elga PureLab Classic UV). The free chlorine concentration was titrated by colorimetric method at $525 \mathrm{~nm}$ after reaction with diethyl-para-phenylenediamine (DPD) ${ }^{22}$. Chloramines solutions were prepared daily and titrated by the DPD method. Then these stock solutions were used to produce chloramines solutions at low concentrations. Monochloramine solutions were prepared through the slowly addition of chlorine in an ammonium chloride (Sigma Aldrich, ACS Reagent> $99.5 \%$ ) solution with a $\mathrm{Cl} / \mathrm{N}$ molar ratio equal to $0.8^{23}$. The two solutions were adjusted beforehand to $\mathrm{pH} 8.5$ using sodium hydroxide. Dichloramine solutions were prepared by acidification, at $\mathrm{pH}=4$ with sulfuric acid, of a monochloramine solution ${ }^{23}$. Trichloramine solutions were obtained by addition of acidified $\left(\mathrm{pH}=4\right.$ with $\left.\mathrm{H}_{2} \mathrm{SO}_{4}\right)$ ammonium chloride solution in a chlorine solution $(\mathrm{pH}=4)^{24}$. THMs solutions were prepared by dilution of pure commercial solutions (Sigma Aldrich) in methanol (stock solution) and UPW (working solution).

\section{Generation of air streams enriched with trichloramine and chloroform}

An air stream enriched with calibrated concentrations of trichloramine was generated using the system previously described by Nguyen et al. ${ }^{25}$. Trichloramine was produced by pumping ammonium sulfate $\left(2.10^{-4} \mathrm{M}\right)$ and sodium hypochlorite $\left(4.10^{-3} \mathrm{M}\right)$ at the same flow $(1.2$ $\mathrm{mL} . \mathrm{min}^{-1}$ ) into a three-neck stirred flask. The $\mathrm{pH}$ was adjusted to 7.2 with a $50 \mathrm{mM}$ phosphate buffer. The trichloramine solution was pumped at $2.4 \mathrm{~mL} \cdot \mathrm{min}^{-1}$ to the top of a stripping column ( $0.7 \mathrm{~m}$ length $\times 5 \mathrm{~cm}$ internal diameter) filled with glass beads. The air stream generated by an air compressor was injected at the bottom of the column at an $80 \mathrm{~L}^{-1} \mathrm{~h}^{-1}$ flow rate. The output air stream was bubbled in two consecutive saturated solutions of sulfamic acid to remove traces of chlorine, monochloramine and dichloramine. The flow was then divided into two streams. One stream was used to regularly check the trichloramine concentration generated by the system, and is called "reference stream". The second stream was diluted with air before reaching the MIMS membrane. The trichloramine concentration was then checked again after the air stream had gone along the MIMS membrane.

Trichloramine concentrations were measured spectrophotometrically after reaction with potassium iodide. The air flow was bubbled into $200 \mathrm{~mL}$ of a potassium iodide solution $(0.2$ M) whose $\mathrm{pH}$ was adjusted to 6 with a phosphate buffer. The triiodide ions formed were dosed with an Uvikon XS spectrophotometer (Secoman) at $353 \mathrm{~nm}$. At least five measurements were done spectrophotometrically to ensure the trichloramine quantification in the air stream. The trichloramine concentrations generated varied from $0.1 \mathrm{mg} \mathrm{NCl}_{3} \cdot \mathrm{m}^{-3}$ to $1.5 \mathrm{mg} \mathrm{NCl}_{3} \cdot \mathrm{m}^{-3}$ 
Calibrated mixtures of chloroform and air were obtained by injecting a concentrated chloroform mixture $\left(1.9 \mathrm{mg} . \mathrm{L}^{-1}\right)$ stored in a $10 \mathrm{~mL}$ gas-tight syringe in the air flow via a syringe pump (Kd Scientific). The final concentration was adjusted via the syringe pump speed. $2.5 \mu \mathrm{L}$ of pure liquid chloroform (Sigma Aldrich, 99+\%) were evaporated in a hermetically closed 2 L glass flask equipped with a magnetic stirrer and glass beads to obtain the concentrated mixture. The syringe was filled via a septum cap.

\section{Membrane Inlet Mass Spectrometer (MIMS)}

The MIMS analyzer (HPR40, Hiden Analytical Ltd.) (Figure 1.a) consisted of two flow-over PDMS membranes, a simple quadrupole, a Faraday detector and a secondary electron multiplier (SEM). The system used was composed of two identical membranes/transfer lines. These were continuously under vacuum while a series of pneumatics valves allowed the "direct to vacuum pump" or "direct to MS source" transfer of the analytes. For water sampling, membranes were immersed in a $100 \mathrm{~mL}$ stirred and hermetically closed flask containing solutions (Figure 1.b). For air sampling, membranes were placed in glass tubes through which the air flowed. Compounds diffused through the membrane ${ }^{26}$ (Figure 1.c) to the transfer line and the electron ionization source $(70 \mathrm{eV})$. The membranes were always at equilibrium in their respective media and only few seconds between valve switching and mass spectrometer (MS) measurement were needed to obtain a stable signal. Signals of $\mathrm{m} / \mathrm{z} 53,84,85,86,88$, and 119 ions were used to analyze the chloramines and signals of $\mathrm{m} / \mathrm{z} 83,129,173$ and 208 ions to analyze the THM; MASsoft 7 software was used to process the data. Chloroform (TCM), bromodichloromethane (BDCM), dibromochloromethane (DBCM) and bromoform (TBM) concentrations were calculated using the following equations:

$$
\begin{aligned}
& {[T B M]=a_{1} I^{173}} \\
& {[D B C M]=a_{2} I^{208}} \\
& {[B D C M]=a_{3} I_{B D C M}^{129} \text { with } I_{B D C M}^{129}=I^{129}-\left(I^{208} \times\left(\frac{129}{208}\right)_{D B C M}\right)} \\
& {[T C M]=a_{4} \times I_{T C M}^{83} \text { with } I_{T C M}^{83}=I^{83}-\left(I_{B D C M}^{129} \times\left(\frac{83}{129}\right)_{B D C M}\right)}
\end{aligned}
$$

Where I represents the signal intensity and $\alpha$ the response factor.

\section{RESULTS}

\section{Quantification of specific DBPs in water and air}

In this section the MIMS performances regarding DBPs measurements in water and air are quantified. Its sensitivity and specificity for the monitoring of two families of molecules (trihalomethanes and inorganic chloramines) are evaluated.

Trihalomethanes Analysis (THMs)

\section{Trihalomethanes in water}

The mass spectra obtained for several targeted DBPs are presented in Figure 2. Although the MIMS source remained at ambient temperature, spectra obtained for THMs are very close to those referred for these compounds ${ }^{27}$ with the same ionization energy. Bromoform (TBM) can be specifically analyzed with the $\mathrm{m} / \mathrm{z} 173$ ion using a constant response factor $\alpha_{1}$ (see Eq.1). The $\mathrm{m} / \mathrm{z} 129$ ion is obtained by the fragmentation of dibromochloromethane (DBCM) and 
bromodichloromethane (BDCM). Therefore, the $\mathrm{m} / \mathrm{z} 208$ ion is necessary for the determination of DBCM concentration despite a lower response factor $\alpha_{2}$ than the ion $\mathrm{m} / \mathrm{z} 129$. (see Eq.2).

The $\mathrm{m} / \mathrm{z} 83$ ion is also obtained by the fragmentation of two compounds: chloroform (TCM) and BDCM. It is therefore necessary to calculate the ion ratio and apply a mathematical correction to simultaneously quantify these two THMs. The fragmentation of DBCM produces the $\mathrm{m} / \mathrm{z} 129$ and $\mathrm{m} / \mathrm{z} 208$ ions with a stable ratio $\left(\frac{129}{208}\right)_{D B C M}$ of $25(\sigma=1.97, \mathrm{n}=46)$. Similarly in the case of BDCM, the ratio between the $\mathrm{m} / \mathrm{z} 83$ and the $\mathrm{m} / \mathrm{z} 129$ ions, $\left(\frac{83}{129}\right)_{B D C M}$, is equal to $14(\sigma=0.65, \mathrm{n}=96)$. It is possible to calculate the intensity corresponding to each THM for the $\mathrm{m} / \mathrm{z} 129$ and $\mathrm{m} / \mathrm{z} 83$ ions using these two ratios. Single compound pure solutions of TCM and BDCM were analyzed to determine the response factors $\alpha_{4}$ and $\alpha_{3}$ for the $\mathrm{m} / \mathrm{z} 83$ and $\mathrm{m} / \mathrm{z} 129$ ions, respectively. Consequently, BDCM and TCM concentrations in complex solutions can be calculated with Eq.3 and Eq.4, respectively (see Material and method section).

The limits of quantification (LOQ) were calculated for THMs according to the NF-T-90-210 method and are slightly higher than values usually reported for brominated THMs during measurement campaigns in French indoor pools ${ }^{28}$. Indeed LOQ amounts to $5.1 \mu \mathrm{g} . \mathrm{L}^{-1}$ for TBM, $5.8 \mu \mathrm{g} . \mathrm{L}^{-1}$ for DBCM and $3.3 \mu \mathrm{g} . \mathrm{L}^{-1}$ and $3.8 \mu \mathrm{g} . \mathrm{L}^{-1}$ for TCM and DBCM respectively. It is noteworthy that the LOQ calculation result depends on the number and on the position of the points on the calibration curve. Hence, analytical performances could be improved by increasing the number of points of the calibration curve, specifically for low concentrations.

\section{Chloroform in air}

Chloroform is the predominant THM in swimming pool air owing to its high volatility. Brominated THMs are usually not monitored in air since their concentrations are negligible compared to chloroform concentration ${ }^{29,30}$. Hence, the MIMS sensitivity in air was evaluated only for chloroform. The limit of quantification calculated according to the NF-T-90-210 method reaches $30 \mu \mathrm{g} \cdot \mathrm{m}^{-3}$, which is low enough to quantify the chloroform in most of the French indoor swimming pools ${ }^{28,31,32}$. However, the calculated LOQ could be lowered by adding calibration points below $20 \mu \mathrm{g} \cdot \mathrm{m}^{-3}$.

\section{Chloramines analysis}

Chloramines in water

Mass spectra of inorganic chloramines show that mono-, di- and trichloramine can be determined by the monitoring of the $\mathrm{m} / \mathrm{z} 53,84$ and 85 ions. Figure 3 shows the signal evolution of these three ions function of chloramines concentrations. It appears that trichloramine can be easily determined in water by using the $\mathrm{m} / \mathrm{z} 84$ ion. This ion is specific to trichloramine because its signal intensity does not increase with mono and dichloramine concentrations. The slight increase observed at high dichloramine concentrations does not affect trichloramine determination in this work since such concentrations are unlikely to occur in swimming pools ${ }^{18,19,33}$.

There are no specific ions for monochloramine and dichloramine. Hence, a mathematical correction is necessary to quantify these two compounds, as previously described for THMs. This lack of specificity could be fixed by decreasing the ionization energy in order to form different pseudomolecular ions. 
An example of signal transition (m/z 84 ion) is presented in Figure 3.c. for trichloramine. These data show that the equilibrium state is obtained within 20 minutes when the membrane is transferred from pure water to a $0.6 \mathrm{mg} \mathrm{Cl} 2 . \mathrm{L}^{-1}$ trichloramine solution. However, the time needed to reach equilibrium decreases with further spikings.

\section{Trichloramine in air}

The mass spectrum of trichloramine is presented in Figure 2.d. A similar spectrum has been realized by Shang and Blatchley ${ }^{17}$ on a different MIMS system. In our case however, impurities contained in the air stream produce highly abundant ions at $\mathrm{m} / \mathrm{z} 52$ and $\mathrm{m} / \mathrm{z} 54$. These undesirable signals are easily suppressed by subtracting the background mass spectrum.

A calibration curve was realized to evaluate the MIMS sensitivity (Figure 4). The m/z 84, 86, 88 and 119 ions were monitored. The $\mathrm{m} / \mathrm{z} 88$ ion seems to be the best ion to measure trichloramine concentration in air. Despite its low signal intensity, this ion produces better sensitivity results than the ions $\mathrm{m} / \mathrm{z} 84$ and $\mathrm{m} / \mathrm{z}$ 86. Its intercept is indeed significantly lower, probably due to reduced interferences in the air. Note that the curve is not linear for concentrations lower than $1 \mathrm{mg} \mathrm{NCl} \cdot \mathrm{m}^{-3}$. This LOQ remains slightly high for trichloramine monitoring in French swimming pool atmospheres where concentrations usually reported range from $0.1 \mathrm{mg} \mathrm{NCl} 3 \cdot \mathrm{m}^{-3}$ to $1 \mathrm{mg} \mathrm{NCl} 3 \cdot \mathrm{m}^{-3} 28,34$.

Figure 4.b. shows the signal transition of the $\mathrm{m} / \mathrm{z} 88$ ion. The equilibrium is reached $10 \mathrm{~min}$ after injection, which is significantly faster than in the aqueous medium. The vapor permeation process occurring in the gaseous phase is indeed faster than the pervaporation process which applies in the aqueous phase, because trichloramine is already evaporated in the first case.

The complexity of trichloramine chemistry motivates the use of chemically stable compounds to study the influence of the analytical conditions on the MIMS signal. Hence in the rest of this paper, the study focuses on the effect of stirring, $\mathrm{pH}$, temperature, ionic strength and air velocity variations using THMs standard solutions.

\section{Effect of analytical conditions}

\section{Agitation rate}

The stirring speed has a significant impact on the observed signal. Figure 5 shows the effect of rotation speed on the signal of the $\mathrm{m} / \mathrm{z} 83$ and 129 ions for a $10 \mu \mathrm{g} . \mathrm{L}^{-1}$ BDCM standard solution in UPW. For low stirring rates (Rate 2 - Rate 3 ), an increase in the steady state signal intensity is observed. Moreover, the time needed to reach equilibrium decreases with the stirrer rotation speed. At higher stirring rates (Rate > 4), no signal variation is observed while increasing the velocity gradient. These observations are explained by a liquid boundary layer existing at the membrane, such that the concentration at the water-membrane interface is lower than in the bulk solution. This boundary layer limits the analyte diffusive flux through the membrane and reduces the mass spectrometer signal. Under high velocity gradient in the solution, this phenomenon becomes negligible since the concentration at the membrane-water interface tends to be equal to the concentration in the bulk aqueous phase. Although the experimental approach used in this study does not allow to fully characterize the hydraulic conditions at the membrane-sample interface, it highlights the importance of hydrodynamic conditions and underlines the necessity of using sufficient agitation to perform reliable analysis by MIMS technique. Similar results were obtained for chloramines, showing that MIMS is fast enough for real-time monitoring of chloramines and THMs concentrations in swimming pool water. The liquid flow rate influence has also been reported in other studies: Yang and Shang ${ }^{35}$ observed a maximum of signal intensity at elevated flow rates. In addition, they 
reported a decrease in the response time while increasing the sample flow rate. These observations support the strong influence of the boundary layer highlighted in this study. On the other hand, Shang and Blatchley ${ }^{17}$ previously reported a positive correlation between liquid flow rate and response time, although they were using the same equipment.

The $\mathrm{pH}$ influence was studied for the range 6.2-9.5, covering the full scope of conditions commonly encountered in pool water (the $\mathrm{pH}$ range authorized for French swimming pool water is $\left.6.9-7.7^{36}\right)$. To compensate for possible variations due to analytical system instability, the two membranes of MIMS were immersed in a reference solution (DBCM $10 \mu \mathrm{g} . \mathrm{L}^{-1}, \mathrm{pH}=$ 6.2) and in a sample (DBCM $10 \mu \mathrm{g} . \mathrm{L}^{-1}$; $\mathrm{pH}$ ranging from 6.2 to 9.5 by $\mathrm{NaOH}$ addition). For a given volume of $\mathrm{NaOH}$ added in the sample solution, the same amount of UPW was added in the reference solution in order to compensate for the dilution effect or loss of THM by evaporation due to the flask opening. MS valves switch every 10 seconds between the reference and sample inlets. Figure 6 shows the analysis of non-averaged raw signal corresponding to the intensity ratio between the sample inlet measurement and the reference inlet measurement. Note that the signal noise was about $10 \%$ when using this relative quantification method. Moreover, no significant signal deviation was observed between the reference solution and the sample for the $\mathrm{pH}$ range 6.2-9.5. Yang and Shang ${ }^{35}$ also reported stable MIMS signals for the analysis of $\mathrm{CNCl}$ and $\mathrm{CNBr}$ on the $\mathrm{pH}$ range 6-8. However, the MIMS signal variations with $\mathrm{pH}$ remains to be tested for other Cl-DBPs before analysis.

\section{Ionic strength}

In some cases swimming pool water is chlorinated using in situ chlorine formation from sodium chloride with electrolytic cell. The salt concentrations should be kept between 4 and 6 g.L. $\mathrm{L}^{-1}$ to ensure optimal disinfection, according to manufacturers' recommendations. Fundamental equations governing the diffusion process are not based on concentration in the aqueous phase but on the molar fraction of the analyte in the aqueous solution. Consequently, the analytes diffusion through the membrane could be altered for high ionic strength solutions in comparison with UPW (zero ionic strength solution). Figure 7 shows the effect of the ionic strength on the signals measured for the $\mathrm{m} / \mathrm{z} 83$ and 129 ions of a BDCM solution. The two membranes were initially placed in two identical BDCM solutions at $10 \mu \mathrm{g} . \mathrm{L}^{-1}$. Once equilibrium was reached, $\mathrm{NaCl}$ was added in the sample solution to increase the sample salinity up to $10 \mathrm{~g} . \mathrm{L}^{-1}$. Figure 7 demonstrates that salinity does not play a significant role in MIMS analysis. However, the maximum salt concentration tested here does not ensure the absence of interference in the particular case of seawater swimming pools, where salt concentration can reach 20 g. $\mathrm{L}^{-1} 37$. At higher $\mathrm{NaCl}$ concentrations $\left(5,8-58 \mathrm{~g} . \mathrm{L}^{-1}\right)$, Miranda et al. ${ }^{38}$ reported ionic strength dependence of MIMS signal for the quantification of four gases. Further experiments at high ionic strength would be necessary to determine if measurements could be performed by MIMS in seawater swimming pools.

\section{Water temperature}

The temperature influence was tested by measuring chloroform and bromoform solutions at different temperatures $\left(15,25\right.$ and $\left.30^{\circ} \mathrm{C}\right)$ and concentrations $\left(6.5\right.$ and $\left.13 \mu \mathrm{g} . \mathrm{L}^{-1}\right)$. Signal intensities are temperature-dependent for all the monitored ions. Increasing temperature $\left(15\right.$ to $\left.30^{\circ} \mathrm{C}\right)$ led to an increase in the MS signal (Figure 8). This can be easily explained by the temperature-dependence of the diffusion coefficient. Therefore, a specific calibration of the instrument at the swimming- 
pool temperature is required before analysis. Alternative approach could consist in using thermostated sampling lines in order to avoid any bias due to temperature fluctuations during sampling campaigns. The temperature effect on dichloramine ${ }^{17}$ and cyanogen chloride ${ }^{35}$ analysis has been reported in the literature. In all cases the optimum temperature was found to be $70^{\circ} \mathrm{C}$ and the response time decreased with an increase in the membrane temperature.

\section{Air flow}

The air speed at the membrane interface influences the analyte diffusion to the membrane and could affect the signal intensity. In this paragraph, the importance of this effect for chloroform quantification is assessed. The chloroform calibration curve was realized at three different air flows to evaluate the air speed influence on the $\mathrm{m} / \mathrm{z} 83$ ion signal intensity (Figure 9). No significant difference was observed at $0.1 \mathrm{~m}^{3} \cdot \mathrm{h}^{-1}$ and $0.5 \mathrm{~m}^{3} \cdot \mathrm{h}^{-1}$. This is mainly due to the low air viscosity. Reynolds numbers are estimated at 370 and 1900 for air flows of $0.3 \mathrm{~m}^{3} \cdot \mathrm{h}^{-1}$ and $0.5 \mathrm{~m}^{3} \cdot \mathrm{h}^{-1}$ respectively, which demonstrates that the flow is laminar along the membrane. Under these conditions, the mass transfer is not significant compared to the diffusion. As the repeatability is good, it can be considered that precise control of the air flow is not a critical parameter.

\section{CONCLUSION}

This work shows that for adequate operating conditions the MIMS method is a robust tool for analyzing DBPs in swimming pools and make diagnostics during facilities operation. However, the measurement of THMs and chloramines requires the monitoring of several ions and mathematical corrections of the signal. THMs are detected using m/z 83, 129, 173 and 208 ions and chloramines with $\mathrm{m} / \mathrm{z} 53,84,85$ and 88 ions. The calculated limits of quantification demonstrate that the MIMS is sensitive enough to accurately monitor THMs in swimming pool water and chloroform in swimming pool air. However, further developments are needed to lower the limit of quantification for trichloramine, before using the MIMS for trichloramine measurements in swimming pool halls. Reducing the membrane thickness and increasing the contact surface may be a solution to increase the signal intensity and will be envisaged as future work.

The $\mathrm{pH}$ and ionic strength of the solution do not significantly influence the determination of THMs. On the other hand, the temperature and hydraulics at the membrane interface must be controlled in order to obtain an accurate determination of DBPs in water. The air speed did not affect the signal intensity for DBPs quantification in pool atmospheres.

Future experimental setup designs will have to consider these influences in order to provide accurate and reliable results.

\section{SPONSORS}

This research program has been founded by the French Agency for Food, Environmental and Occupational Health \& Safety as well as the region Bretagne.

\section{ACKNOWLEDGEMENTS}

The authors are grateful to Nicolas Garandel for his precious technical support. They also would like to express their sincere thanks to colleagues who improved the quality of this document. 


\section{REFERENCES}

1. Lefèvre $B$, Thiery $P$. Les principales activités physiques et sportives pratiquées en France en 2010. Bulletin de statistiques et d'études. Ministère Sports N¹1-02. 2011.

2. Alkatan M, Baker JR, Machin DR, et al. Improved Function and Reduced Pain after Swimming and Cycling Training in Patients with Osteoarthritis. J Rheumatol. 2016;43(3):666-672. doi:10.3899/jrheum.151110

3. Merom D, Stanaway FF, Handelsman DJ, et al. Swimming and Other Sporting Activities and the Rate of Falls in Older Men: Longitudinal Findings From the Concord Health and Ageing in Men Project. Am J Epidemiol. 2014;180(8):830-837. doi:10.1093/aje/kwu199

4. Uyan ZS, Carraro S, Piacentini G, Baraldi E. Swimming pool, respiratory health, and childhood asthma: Should we change our beliefs? Pediatr Pulmonol. 2009;44(1):31-37.

doi:10.1002/ppul.20947

5. Geiger KR, Henschke N. Swimming for children and adolescents with asthma. Br J Sports Med. 2015;49(12):835-836. doi:10.1136/bjsports-2013-093397

6. Brüggemann T, Ávila L, Fortkamp B, et al. Effects of Swimming on the Inflammatory and Redox Response in a Model of Allergic Asthma. Int J Sports Med. 2015;36(07):579-584. doi:10.1055/s0034-1395588

7. De Laat J, Berne F, Brunet R, Hue C. Sous-produits de chloration formés lors de la désinfection des eaux de piscines. Étude bibliographique. Eur J Water Qual. 2009;40(2):109-128. doi:10.1051/water/2009008

8. Bernard A, Carbonelle S, Michel O, et al. Lung hyperpermeability and asthma prevalence in schoolchildren: unexpected associations with the attendance at indoor chlorinated swimming pools. Occup Environ Med. 2003;60(6):385-394. doi:10.1136/oem.60.6.385

9. Lévesque B, Duchesne J-F, Gingras S, et al. The determinants of prevalence of health complaints among young competitive swimmers. Int Arch Occup Environ Health. 2006;80(1):32-39. doi:10.1007/s00420-006-0100-0

10. Massin N, Bohadana AB, Wild P, Hery M, Toamain JP, Hubert G. Respiratory symptoms and bronchial responsiveness in lifeguards exposed to nitrogen trichloride in indoor swimming pools. Occup Environ Med. 1998;55(4):258-263. doi:10.1136/oem.55.4.258

11. Nickmilder M, Bernard A. Ecological association between childhood asthma and availability of indoor chlorinated swimming pools in Europe. Occup Environ Med. 2006;64(1):37-46. doi:10.1136/oem.2005.025452

12. Jacobs JH, Spaan S, van Rooy GBGJ, et al. Exposure to trichloramine and respiratory symptoms in indoor swimming pool workers. Eur Respir J. 2007;29(4):690-698. doi:10.1183/09031936.00024706

13. Tableau $n^{\circ} 66$ du Décret $n^{\circ} 2003-110$ du 11 février 2003. 2003. https://www.legifrance.gouv.fr/affichCodeArticle.do;jsessionid=FA1469CE51D6F4B9E97DB6AC 56288ADD.tpdila23v_2?cidTexte=LEGITEXT000006073189\&idArticle=LEGIARTI000006750197\& dateTexte=20170130\&categorieLien=id\#LEGIARTI000006750197. Accessed January 30, 2017. 
14. Zwiener C, Richardson SD, De Marini DM, Grummt T, Glauner T, Frimmel FH. Drowning in Disinfection Byproducts? Assessing Swimming Pool Water. Environ Sci Technol. 2007;41(2):363372. doi:10.1021/es062367v

15. Afifi M, Blatchley ER. Effects of UV-based treatment on volatile disinfection byproducts in a chlorinated, indoor swimming pool. Water Res. 2016;105:167-177. doi:10.1016/j.watres.2016.08.064

16. Kristensen $\mathrm{GH}$, Klausen MM, Andersen HR, et al. Full scale test of UV-based water treatment technologies at Gladsaxe Sport Centre - with and without advanced oxidation mechanisms. Swim Pool Spa Int Conf Lond. 2009.

17. Shang C, Blatchley ER. Differentiation and quantification of free chlorine and inorganic chloramines in aqueous solution by MIMS. Environ Sci Technol. 1999;33(13):2218-2223. doi:10.1021/es9812103

18. Weaver WA, Li J, Wen Y, Johnston J, Blatchley MR, Blatchley III ER. Volatile disinfection byproduct analysis from chlorinated indoor swimming pools. Water Res. 2009;43(13):3308-3318. doi:10.1016/j.watres.2009.04.035

19. Weng S, Blatchley ER. Disinfection by-product dynamics in a chlorinated, indoor swimming pool under conditions of heavy use: National swimming competition. Water Res. 2011;45(16):52415248. doi:10.1016/j.watres.2011.07.027

20. Ketola RA, Kotiaho T, Cisper ME, Allen TM. Environmental applications of membrane introduction mass spectrometry. J Mass Spectrom. 2002;37(5):457-476. doi:10.1002/jms.327

21. Kristensen GH, Klausen MM, Hansen VA, Lauritsen FR. On-line monitoring of the dynamics of trihalomethane concentrations in a warm public swimming pool using an unsupervised membrane inlet mass spectrometry system with off-site real-time surveillance. Rapid Commun Mass Spectrom. 2010;24(1):30-34. doi:10.1002/rcm.4360

22. APHA. Standard Methods for the Examination of Water and Wastewater. 21rst ed. Washington, DC: American Public Health Association; 2005.

23. Schreiber IM, Mitch WA. Influence of the order of reagent addition on NDMA formation during chloramination. Environ Sci Technol. 2005;39(10):3811-3818. doi:10.1021/es0483286

24. Soltermann F, Widler T, Canonica S, von Gunten U. Comparison of a novel extraction-based colorimetric (ABTS) method with membrane introduction mass spectrometry (MIMS): Trichloramine dynamics in pool water. Water Res. 2014;58:258-268. doi:10.1016/j.watres.2014.03.059

25. Nguyen T-H, Chevallier E, Garcia J, et al. Innovative colorimetric sensors for the detection of nitrogen trichloride at ppb level in swimming pools. Sens Actuators B Chem. 2013;187:622-629. doi:10.1016/j.snb.2013.07.041

26. Hiden Analytical. Hiden HPR40 Membrane Inlet Mass Spectrometer System. 2013.

27. NIST Mass Spec Data Center, S.E. Stein, director. Mass spectra. In: NIST Mass Spectral Library (NIST 14). National Institute of Standards and Technology. Gaithersburg MD, 20899: P.J. Linstrom and W.G. Mallard; 2014. 
28. Le Cossec C, Laurent A-M, Person A, Rouvié-Laurie I, Beaubestre C. Teneurs en trichloramine et trihalométhanes dans l'air ou l'eau des piscines publiques parisiennes et impact de différents procédés de traitement de l'eau des bassins. Pollut Atmos. 2016;(228):73-86.

29. Lourencetti C, Grimalt JO, Marco E, et al. Trihalomethanes in chlorine and bromine disinfected swimming pools: Air-water distributions and human exposure. Environ Int. 2012;45:59-67. doi:10.1016/j.envint.2012.03.009

30. Erdinger L, Kühn KP, Kirsch F, et al. Pathways of trihalomethane uptake in swimming pools. Int J Hyg Environ Health. 2004;207:571-575.

31. Bessonneau V, Derbez M, Clément $M$, Thomas O. Determinants of chlorination by-products in indoor swimming pools. Int J Hyg Environ Health. 2011;215:76-85.

doi:10.1016/j.ijheh.2011.07.009

32. Afsset. Évaluation des risques sanitaires liés aux piscines. Partie 1 : piscines réglementées. June 2010.

33. Richardson SD, DeMarini DM, Kogevinas M, et al. What's in the pool? A comprehensive identification of disinfection by-products and assessment of mutagenicity of chlorinated and brominated swimming pool water. Environ Health Perspect. 2010;118(11):1523-1530. doi:10.1289/ehp.1001965

34. Gérardin F, Cloteaux A, Midoux N. Modeling of variations in nitrogen trichloride concentration over time in swimming pool water. Process Saf Environ Prot. 2015;94:452-462. doi:10.1016/j.psep.2014.10.004

35. Yang $\mathrm{X}$, Shang $\mathrm{C}$. Quantification of aqueous cyanogen chloride and cyanogen bromide in environmental samples by MIMS. Water Res. 2005;39(9):1709-1718. doi:10.1016/j.watres.2005.01.030

36. Arrêté Du 7 Avril 1981 Relatif Aux Dispositions Techniques Applicables Aux Piscines. Journal Officiel de la République Française.

37. Boudenne J-L, Parinet J, Demelas C, Manasfi T, Coulomb B. Monitoring and factors affecting levels of airborne and water bromoform in chlorinated seawater swimming pools. J Environ Sci. 2017;58:262-270. doi:10.1016/j.jes.2017.05.022

38. Miranda LD, Byrne RH, Short RT, Bell RJ. Calibration of membrane inlet mass spectrometric measurements of dissolved gases: Differences in the responses of polymer and nanocomposite membranes to variations in ionic strength. Talanta. 2013;116:217-222. doi:10.1016/j.talanta.2013.05.014

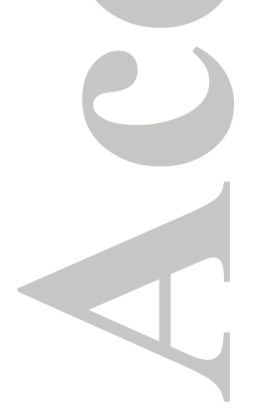



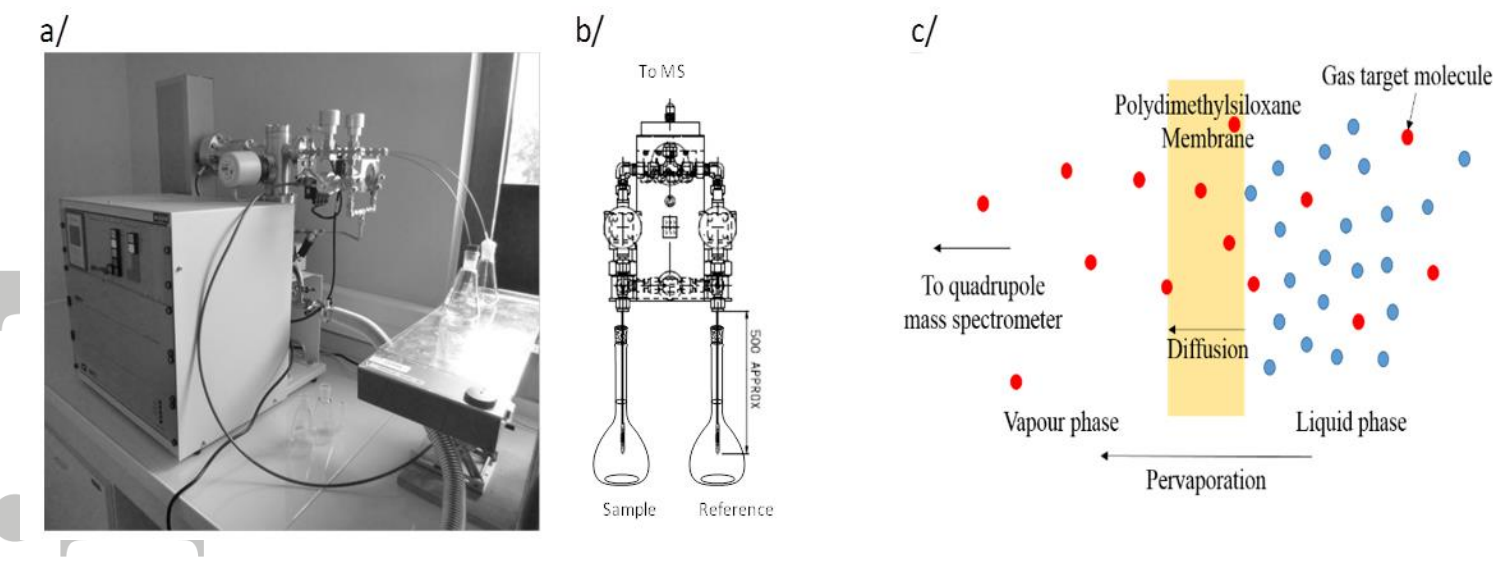

Figure 1: a / MIMS HPR-40 DSA. b / Illustration of the valve system. c / Pervaporation principle at the MIMS membranes ${ }^{26}$ 


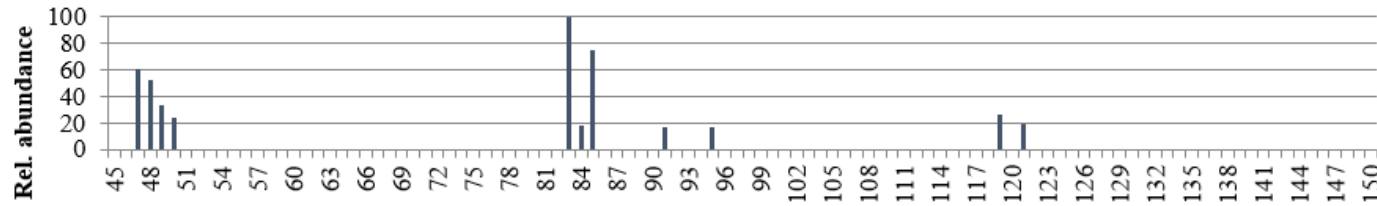

$\mathbf{m} / \mathbf{z}$

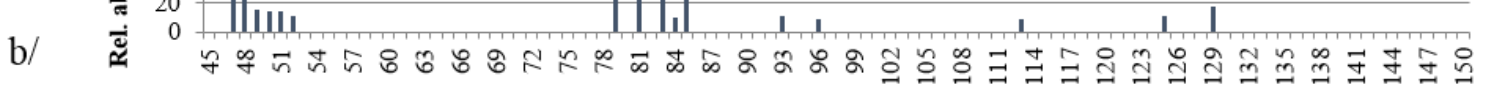

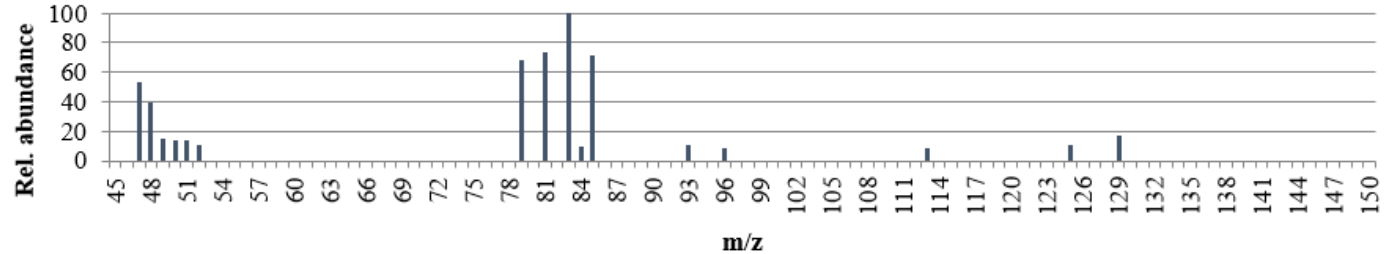

c/

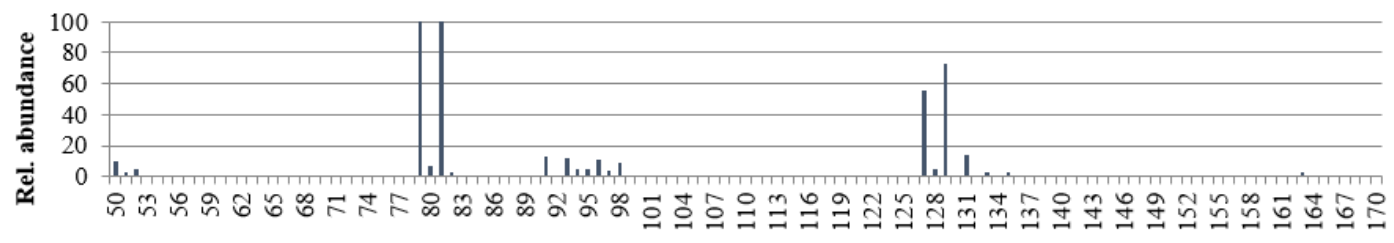

$\mathbf{m} / \mathbf{z}$

d

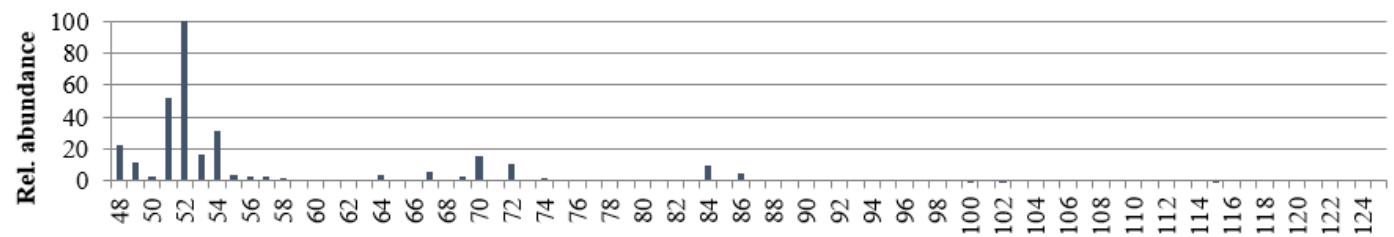

$\mathbf{m} / \mathbf{z}$

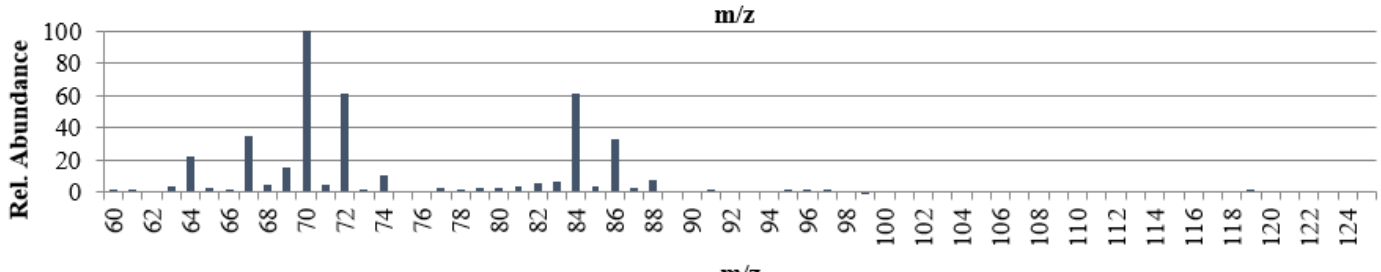

$\mathbf{m} / \mathbf{z}$

Figure 2: Mass spectra obtained for several targeted DBPs (70 eV) a) Chloroform in water $(100 \mu \mathrm{g} / \mathrm{L})$ b) Bromodichlorometthane in water $(100 \mu \mathrm{g} / \mathrm{L}) \mathrm{c}$ ) Dibromochloromethane in water $(200 \mu \mathrm{g} / \mathrm{L}) \mathrm{d})$ and e) Trichloramine in air $(2 \mathrm{mg} / \mathrm{m} 3)$ 

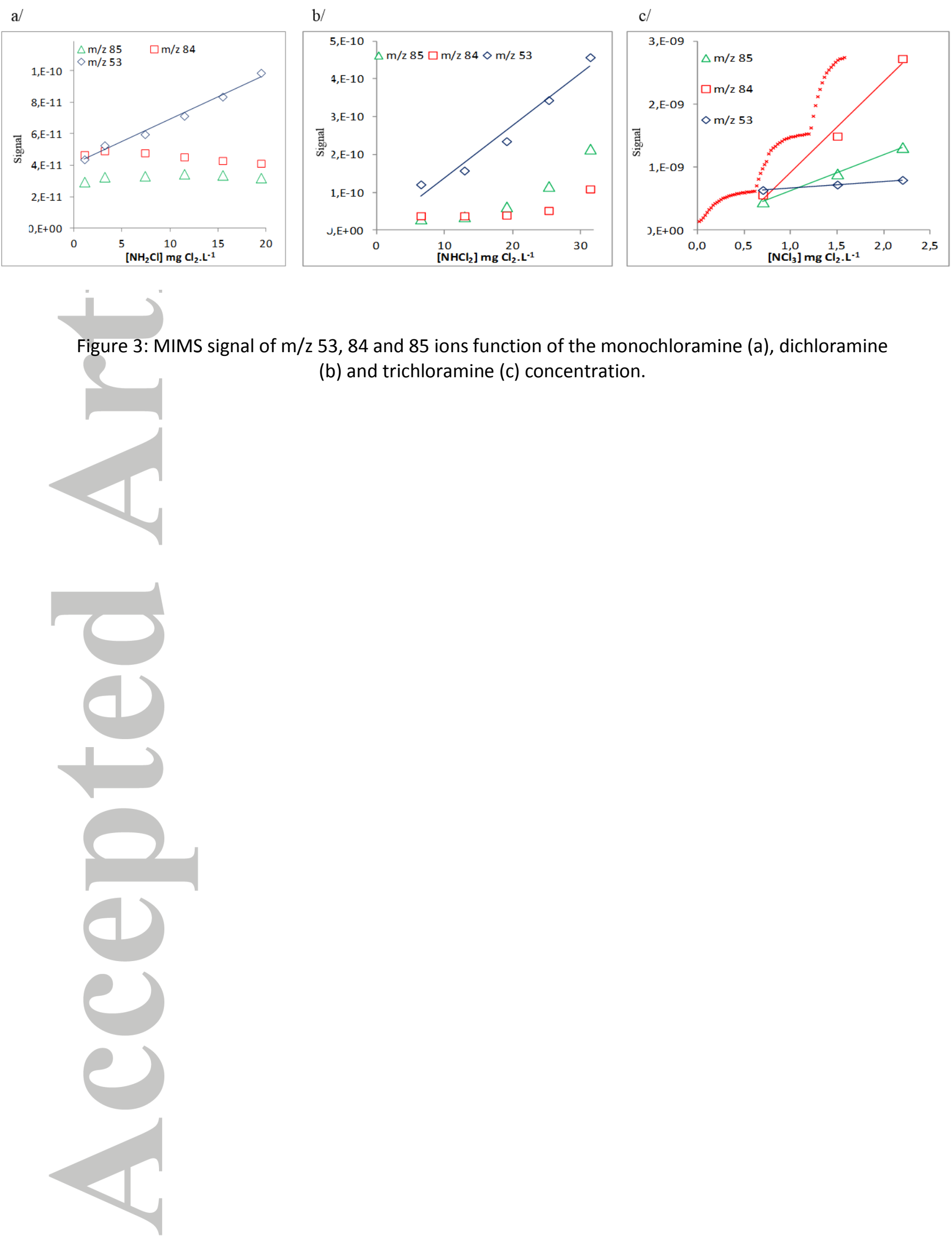

(b) and trichloramine (c) concentration. 


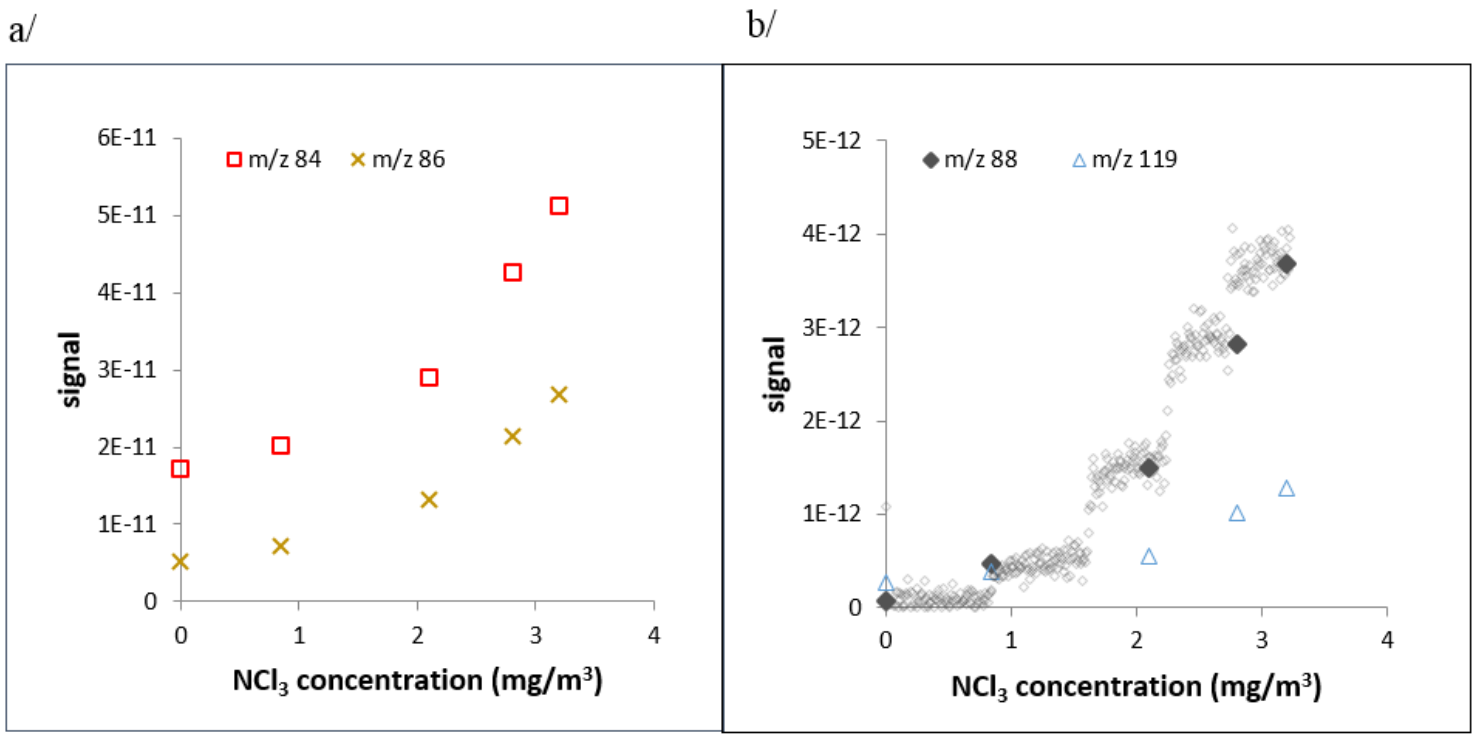

Figure 4: MIMS signal of $\mathrm{m} / \mathrm{z} 84,86,88$ and 119 ions function of the trichloramine concentration in the air stream

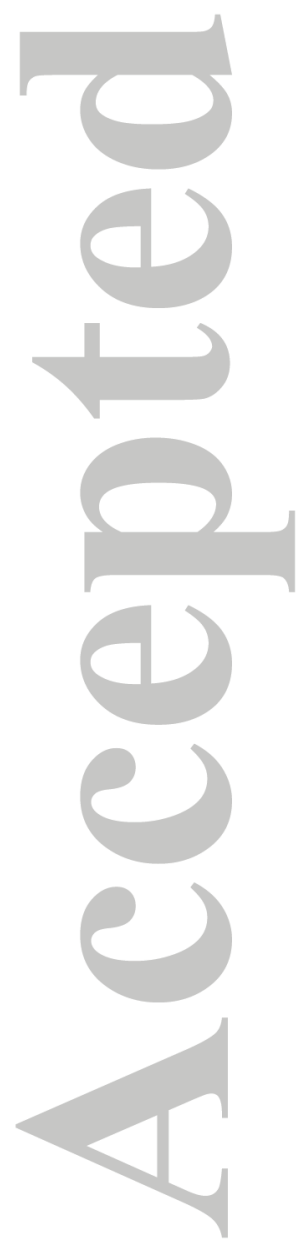




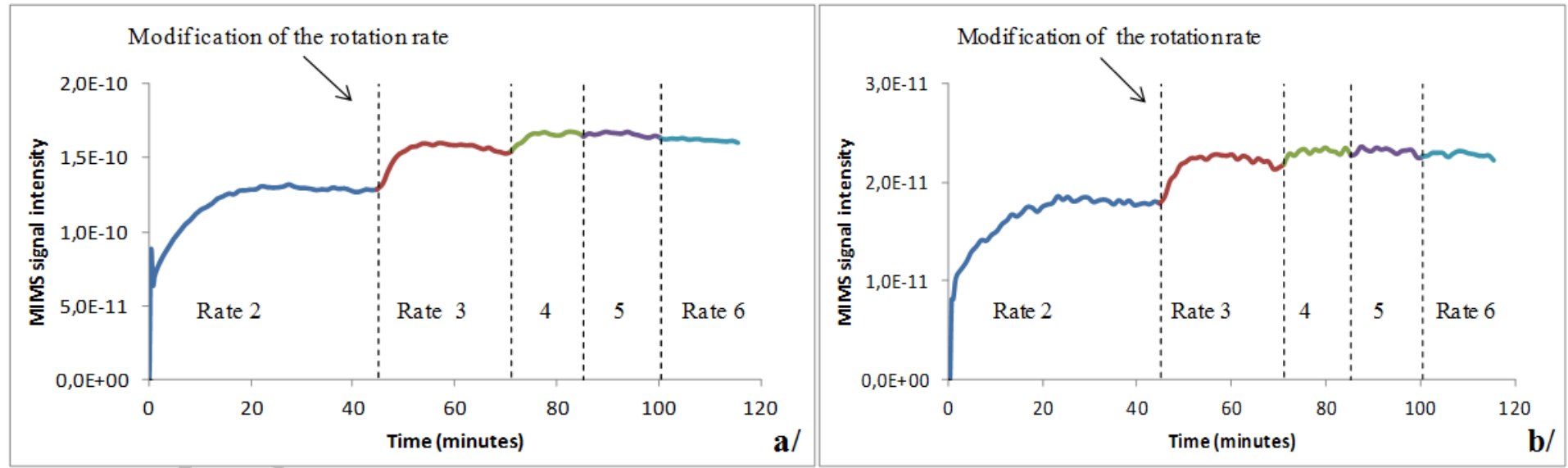

Figure 5: Stirring rate influence on BDCM ion signal intensity at m/z $83(\mathrm{a} /)$ and $\mathrm{m} / \mathrm{z} 129(\mathrm{~b} /)$.
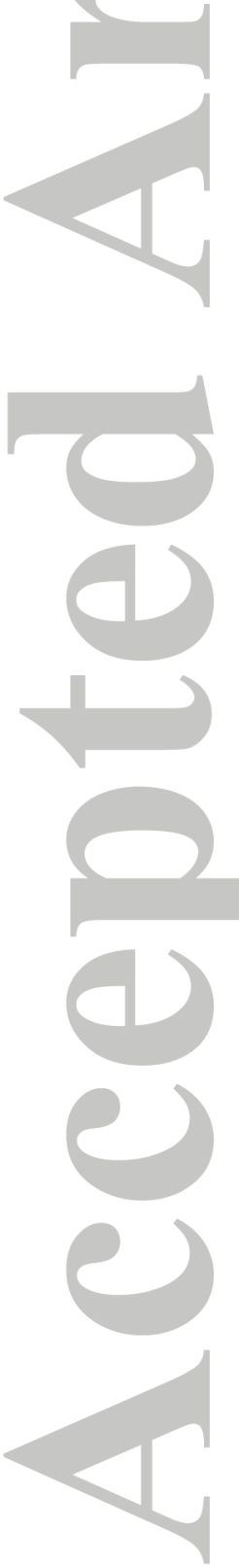

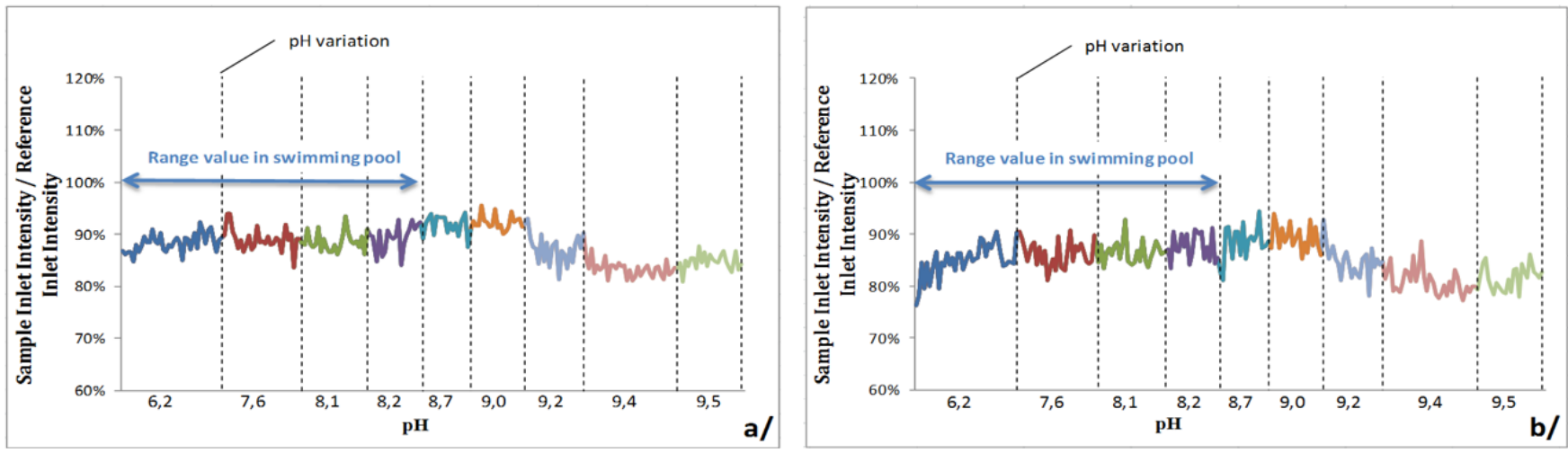

Figure 6: Effect of $\mathrm{pH}$ on relative signal intensities of the $\mathrm{m} / \mathrm{z} 83(\mathrm{a} / \mathrm{)}$ and of the $\mathrm{m} / \mathrm{z} 129(\mathrm{~b} /)$ ions for BDCM. 


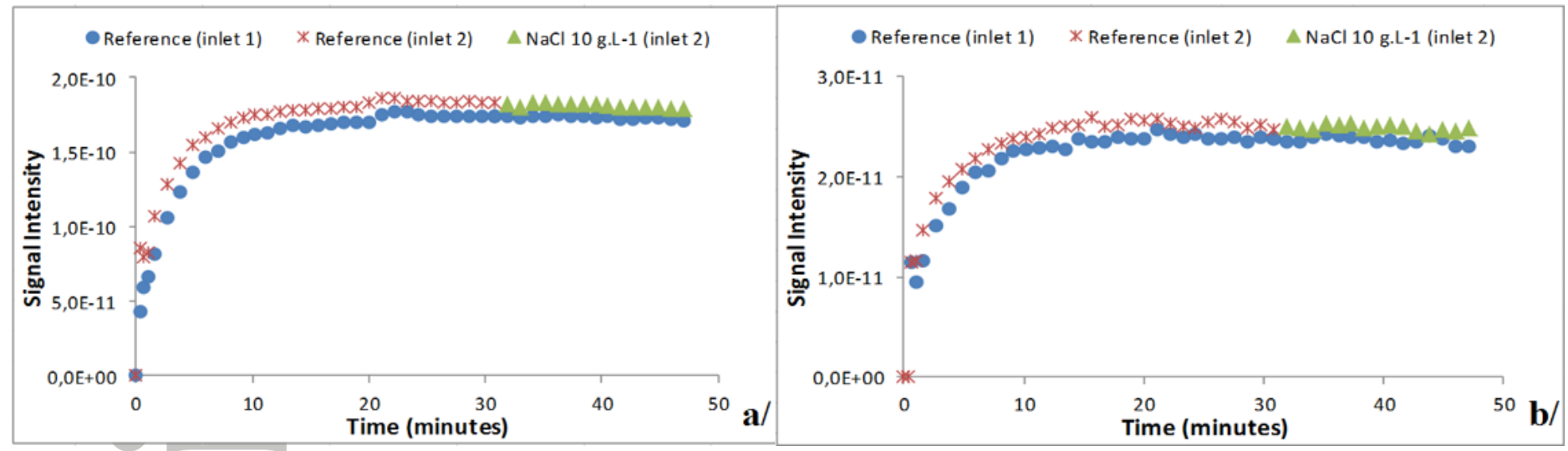

Figure 7: Effect of salt on relative ion signals intensities of the $\mathrm{m} / \mathrm{z} 83(\mathrm{a} /)$ and $\mathrm{m} / \mathrm{z} 129(\mathrm{~b} /)$ for BDCM
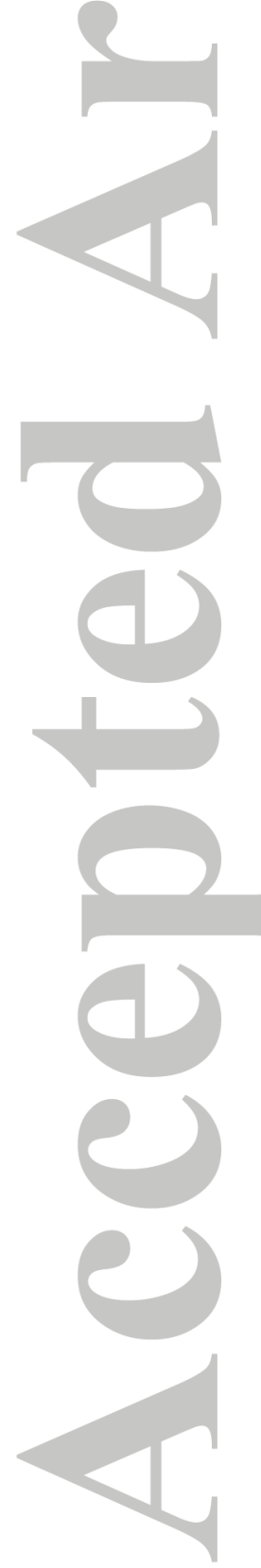


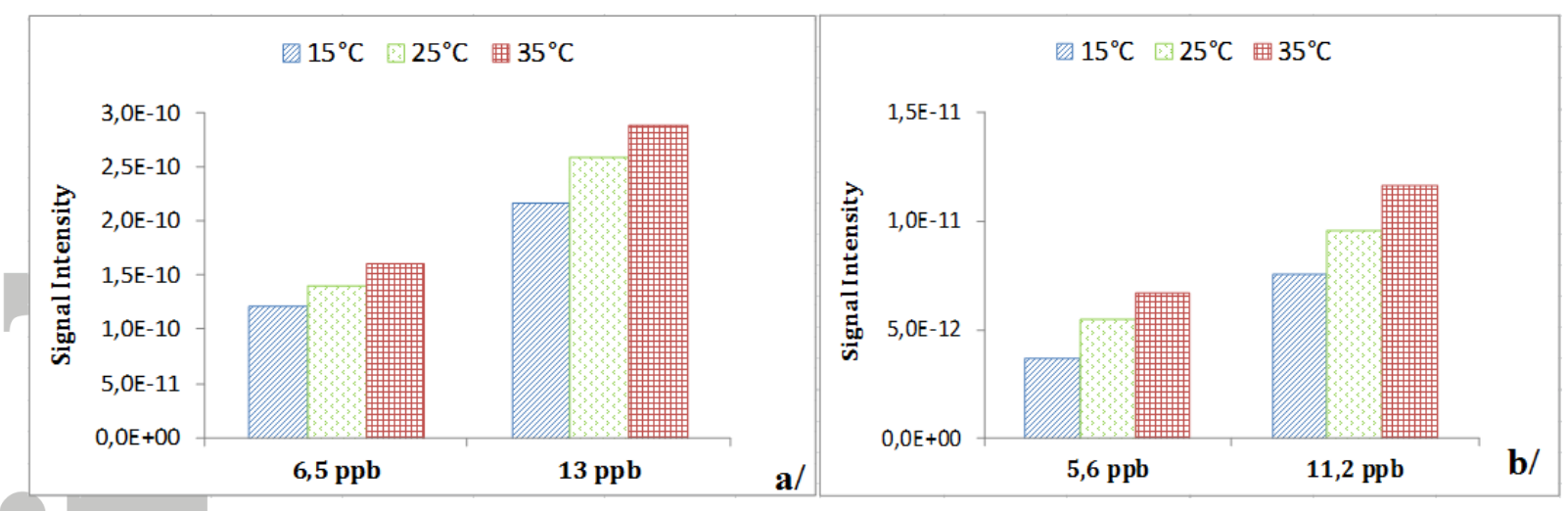

Figure 8: Temperature influence on chloroform signal intensity $(\mathrm{a} / \mathrm{)}$ ) and bromoform signal intensity (b/) 


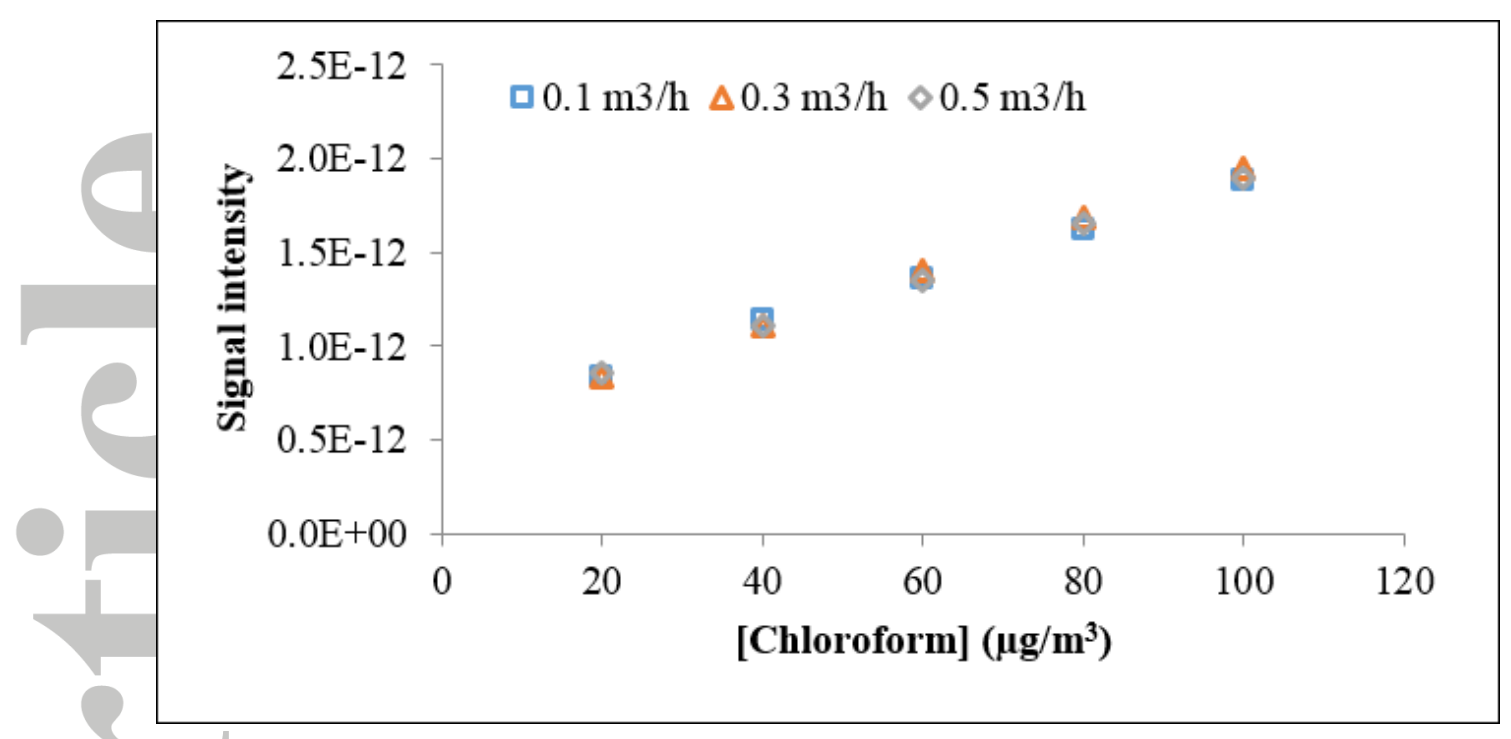

Figure 9: MIMS calibration curve for chloroform ( $\mathrm{m} / \mathrm{z} 83$ ion) at three different air velocities
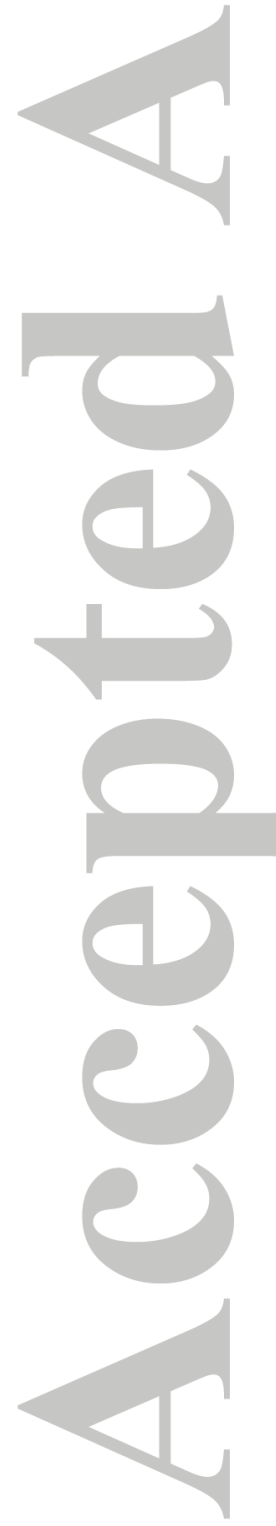